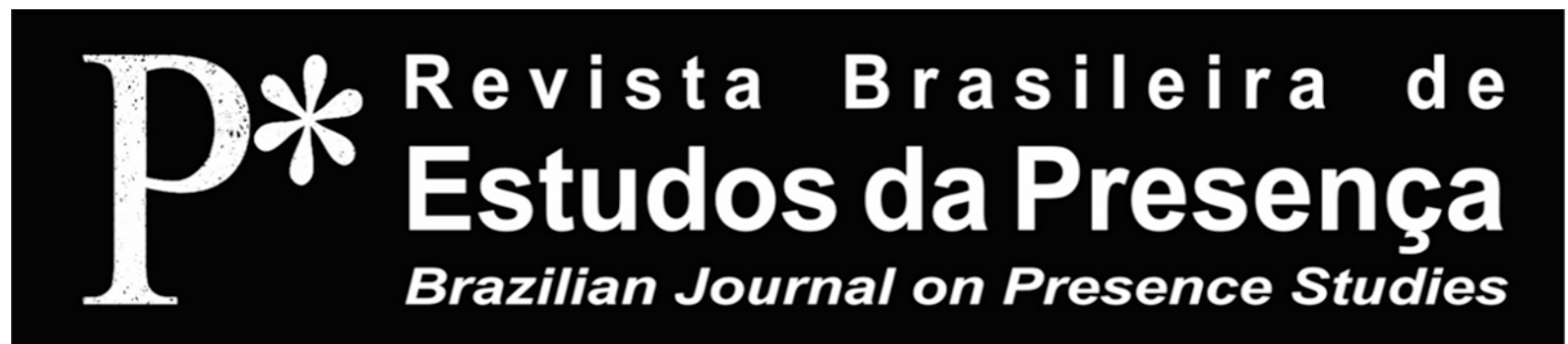

\title{
What Role could Presence Play in the Practices of Academia? On the performativity of theory in the context of Performance Philosophy
}

\author{
Alice Lagaay' \\ Anna Seitz ${ }^{1, ~ I I ~}$ \\ 'Hamburg University of Applied Sciences - Hamburg, Germany \\ "University of Bremen - Bremen, Germany
}

ABSTRACT - What Role could Presence Play in the Practices of Academia? On the performativity of theory in the context of Performance Philosophy - The dialogue discusses the role presence could be permitted to play in academic situations of co-presence with others (in comparison to the importance of presence in artistic contexts). It ponders the extent to which conventional academic forms, quite apart from seeking to guarantee objectivity in theory, actually pre-determine, or in fact limit, the communicability of theoretical content. The conversation points to the need for a new dramaturgical attentiveness to the performativity of theory and calls for an innovative approach to the formats in which the questions and results concerning various fields in the humanities could be presented and negotiated more successfully.

Keywords: Presence. Performance Philosophy. Formats of Knowledge. Interdisciplinarity. Performative Contradictions.

RÉSUMÉ - Quel Rôle pourrait Jouer la Présence dans les Pratiques des Sciences Humaines? Un dialogue sur la performativité de la théorie dans le contexte de la philo-performance - Le dialogue thématise le rôle que pourrait jouer la présence dans des situations académiques de co-présence avec d'autres (par rapport à l'importance de la présence dans des contextes artistiques). Il s'interroge sur la mesure dans laquelle, au-delà d'idéalement garantir l'objectivité théorique, les formes académiques conventionnelles ont tendance à déterminer ou même à limiter réellement la transmissibilité de contenu théorique. La conversation souligne la nécessité d'une nouvelle approche dramaturgique par rapport à la performativité de la théorie et appelle à un développement de sensibilités pour de nouveaux formats alternatifs dans lesquels les résultats et les questions de divers domaines des sciences humaines pourraient être présentés et négociés avec plus de succès.

Mots-clés: Présence. Philo-performance. Formats de Connaissance. Interdisciplinarité. Contradictions Performatives.

RESUMO - Que Papel a Presença poderia Desempenhar nas Práticas Acadêmicas? Sobre a performatividade da teoria no contexto da Filosofia-Performance - $\mathrm{O}$ diálogo discute o papel desempenhado pela presença em situações acadêmicas de copresença com outras pessoas (em comparação com a importância da presença em contextos artísticos). Questiona a medida em que as formas acadêmicas 
convencionais, para além de buscar garantir a objetividade teórica, na verdade pré-determinam ou, de fato, limitam a transmissibilidade do conteúdo teórico. A conversa aponta para a necessidade de uma nova atenção dramatúrgica à performatividade da teoria, e apela por uma abordagem inovadora aos formatos como as perguntas e os resultados referentes aos diversos campos nas humanidades poderiam ser apresentados e negociados com maior sucesso.

Palavras-chave: Presença. Filosofia-Performance. Formatos de Conhecimento. Interdisciplinaridade. Contradiçóes Performativas.

The following dialogue is the result of an encounter between Alice Lagaay, philosophy professor and co-founding convener of the Performance Philosophy network, and dramaturg and philosopher Anna Seitz. In this conversation they discuss various ways in which a performative lens can help to enhance the role of presence in the practices of research, teaching and learning at the university where standardized processes of linearization are increasingly becoming habitualised to negative effect.

Anna Seitz (A.S.): Comparing artistic and academic practices with respect to the question of presence, it is noticeable that within artistic contexts presence almost always leads directly to questions of format, whereas within the sciences or German Geisteswissenschaften (humanities) in particular, the questioning of formats of knowledge (including formats of knowledge production and communication) is something of a taboo. The particular relation that an artwork draws between form and content is generally considered an important criterion for the quality of the work; in academia, in contrast, adherence to a long-established form is of central importance. Moreover, when it comes to written presentations, what counts as the appropriate scientific form to adhere to is generally quite strictly defined for each given academic discipline. In presentations of one's work in situations of physical co-presence, such as in conferences, seminars or lectures, questions of format are rarely the object of much reflection or scrutiny. Therefore, in the dramatic arts the quality of presence that can be ascribed to a performer will clearly affect the audience's appreciation of the art in question, whereas in the case of academia, the quality of a lecturer's performative presentation, whether it is perceived as good or not, is rarely openly discussed, let alone analysed. It is as if there were little or no connection between performative form and the actual content of the presentation. But it's simply not true, of course, that performance has no bearing on content. If a scientist (whatever 
their field, be they from the natural sciences or humanities) presents the results of their work by mumbling a pre-written text in complex jargon-laden sentences without once looking up from their paper (a situation that anyone who has ever been to an academic conference will know happens quite often), then the audience are not able to engage with, let alone assess, the content of the work being offered up for discussion because they simply cannot grasp what has been said. We do not tend to admit that this is the case for fear of being perceived as bad or ignorant scientists. Perhaps this is also why we do not demand that different scientific performative practices be introduced and instead prefer to suffer through seemingly interminable panels and seminars pretending to know what is being discussed - so that no doubts can be raised amongst our peers regarding our own academic competence. If anyone dares suggest that alternative formats of practice might perhaps be worth exploring, you can be sure that someone will be quick to counter with the reminder that rigorous science surely requires complex formats and that, ultimately, we are not here (at this conference, say) to be entertained but to engage in hard work. The results of rigorous science must not be flattened and trivialized, they will say, by adopting the format of TED Talks - perish the thought - and bullet points. This may indeed be the case. But TED Talks and bullet points are surely not the only imaginable alternatives. On the contrary, it is important, I believe, that we search for, and elaborate, formats of knowledge that no longer prevent but actually make it possible for complex content to be shared in situations of physical co-presence, something that is all too rarely explored at present even and especially in contexts where the content of the research would lead one to expect otherwise (e.g. in theatre and performance studies, the social sciences and other disciplines where the observation of practices is central to the expertise at hand). One question must be, what role does the spatial and temporal co-presence, as Erika Fischer-Lichte would call it (Fischer-Lichte, 2015), of scientists actually play? There can be no doubt that complex writing is more easily read and digested at home alone rather than when (badly) read out loud to an audience. The question therefore becomes: what can we do better in situations of co-presence with others and our peers than alone at our desks? 
Alice Lagaay (A.L.): At stake amongst other things here, I think, is the complex interrelation between notions of objectivity and subjectivity with regard to our concept and understanding of what counts as truth. What has led to the conventional academic formats we know and has also no doubt helped to sustain them over generations, is the idea that scientific truth must be objective and universal and therefore free from, and distinguishable from, subjective perspectives, personal idiosyncrasies (including vocal grain or tonality); free, moreover, from anything that might be reducible to mere rhetoric. This is especially true, and has a particular tradition and understandable rationale, in German history since the rise of fascism in the 1930s, which led to the Holocaust and the Second World War. Since then, sound Wissenschaft (science) must certainly not stir the emotions or be easily accessible. Dry discourse delivered in a monotonous voice has tended to be equated with rigorous and sound, critical left-leaning theory, whereas anything that speaks to the masses is to be regarded with scepticism - especially if it appeals to people's senses and baser instincts rather than challenging their intellect. Although generated from a very different culture (i.e. international anglophone and business-related), the success of the TED Talk format could be interpreted as the logical counterpart to this same convention, the polar opposite to academic jargon-laden discourse, if you will. TED Talks cater to a feel good aesthetic, delivering bit-sized snippets of well-packaged scientific sound bites that just might inspire you to make a small change in your lifestyle but are guaranteed to make you feel that those were 15 minutes well spent. There are a host of rhetorical tricks at play, which some particularly clever TED talkers have made a point of pointing out $^{1}$. What TED Talks and the dry monotonous discourse delivered much of the time at scientific conferences certainly have in common is that their content is pre-established and static at the moment of delivery. In other words, their ideal of communication is one-directional and corresponds to the basic - and by now quite outdated - information transmission model of communication (Shannon; Weaver, 1979 [1949]) $)^{2}$. The speakers in either case do not aim to generate knowledge by drawing on the opportunity that is given by being in a situation of temporal and spatial co-presence with an audience. To do so would require stepping out of their rehearsed safe zone in order to let something happen that is improvised or unexpected - it 
would be to risk letting something new emerge performatively. We may wonder whether this might not be the actual point and true potential of coming together in the first place: to generate and explore a thinking in the collective, a form of thinking that is precisely impossible for isolated individuals. It is bewildering to me that the experience of actually thinking (something) together is so rare and not more eagerly sought by academics. As philosophers, for instance, we are constantly drawing on the collective, our thought is so often based on others' thinking for a start; and yet, when we present our work to our colleagues, it's as if suddenly we are no longer part of a larger collective - the collective tends to be pushed to one side we are instead stand-alone egos (and the same is the case of the audience at academic conferences; it is not a collective body but very much an assembly of individuals). Yet, paradoxically, the conference format constitutes one of the rare opportunities to enter into a collective exchange. So why do we allow the organization of the formats to cause us to miss the opportunity to enter into a collective thought process? I find it difficult to understand why we do not seize these opportunities to come together, that is, to connect in some way, to exchange and to develop ideas together, rather than merely assembling in one place and having texts read to us that we could as easily have read at home alone. That practice would only make sense to me if we were at least (also) to show an interest in how a text is presented, but the how of a lecture is strangely taboo in academic circles. It is surely all the more pressing that academics reflect on the performative potential of the formats in which they deliver knowledge, given the nature of the information society in which we now live, where increasingly questionable sources and sites are not only generating and sharing unverified news at high speed but also increasingly influencing political outcomes performatively in real time. More than ever before perhaps are the results of well-reflected and digested critical theory in the humanities, and the knowledge generated in various fields of study at university at risk of becoming irrelevant if those dealing in this knowledge do not make more effort to render it accessible and interdisciplinary.

A.S.: Issues of performativity have been fashionable in cultural studies and philosophy for some time, but they are hardly ever applied to one's own academic performances. This sometimes reminds me of the nineteenth- 
century understanding of theatre as being nothing other than text brought to the stage, a conception that - fortunately - seems thoroughly absurd to us today. The question is whether we do not perhaps need a performative culture of philosophy (and of scholarly content in general) that does not merely ask what a lecture is about but also how it is performed. Finally, it has long been known (precisely in philosophy) that form contributes decisively to content. My question is, why then are we, as conscientious scientists, even allowed to ignore forms of performance?

A.L.: For some time now, we have seen a growing number of initiatives that seek new formats to impart and explore philosophical content. Such initiatives can be found both inside and outside of the purely academic framework of universities and are occurring, above all, at the intersections where science and art meet. Examples of this development in the German-speaking world include the association Verein Expedition Philosophie e.V. ${ }^{3}$, based in Leipzig, which hosts a regular series of events called SoundcheckPhilosophie $e^{4}$, and the Viennese festival series Philosophy on Stage ${ }^{5}$. On the international level, these and other comparable activities are assembled under the auspices of the new research field Performance Philosophy. The many different projects and approaches that describe themselves as Performance Philosophy cannot easily be reduced to a common denominator. Nevertheless, many are motivated by the desire or need to maintain and impart scientific insights into content not solely discursively but by seeking to embody and further investigate theory by drawing on the means and methods of performance (in the broadest sense). Although, as noted, there is not (yet) a clear common denominator in the approaches to solutions of these initiatives, they seem to have independently come to the shared conclusion that there is a certain urgency today that we stop merely producing new content but that we begin to question existing philosophical formats. In the international context, this occurred quite successfully at the Third Biennial Performance Philosophy Conference held in Prague in 2017 under the title How Does Performance Philosophy Act? Ethos, Ethics, Ethnography ${ }^{6}$. Anna, you were also a member of the programme planning committee at this conference. In what light do you see these developments?

A.S.: As you have already suggested, every innovation always implies a certain criticism of the status quo, and increasingly philosophers seem to agree 
on this criticism. If we want to take a question such as How does Performance Philosophy act seriously, it is not satisfactory to address the issue in the usual standard conference format, but we have to question our formats as well, since these, after all, to a large extent structure our action. It therefore becomes a question of exploring the conference, too, in terms of performance (that is, both with regard to its performativity and as a performance) and, following our line of questioning further, engaging with the ethos and the ethics of its performativity. Performance Philosophy strives for an exchange between disciplines and whose basic premise has to be the dismantling of the hierarchies of knowledge cultures and their formats. Rather than merely allowing them to coexist side by side, we wanted to explore their permeability at the conference. The standard format of conferences is increasingly being criticized, as you rightly observe, but usually we lack the time and perhaps also the courage to find alternatives. Performance Philosophy wants to make a free space available in which representatives of different disciplines experiment together in terms of both content and format and thus train their sense for alternatives. The dramaturgy of the conference created such an experimental setup, which we then evaluated over the course of the conference. It was essentially about becoming aware of our own blind spots; it was about exploring a distanced look at our own culture and making it possible to see its aesthetic and ethical dimensions in order to reflect on how we really act (usually unreflectively) and how we might act better by distancing ourselves from that. In relation to the ethos and the ethics of Performance Philosophy, another urgent concern for us, in addition to dismantling the hierarchies of forms of knowledge, was to encourage a democratization of input/output and dialogical exchange in the form of thinking and speaking jointly. We wanted to improve the opportunities for knowledge to be not merely consumed passively but generated interactively. Usually, this practice is simply not part of a standard conference format, as can be seen clearly from its temporal structures. If a twenty-minute lecture is meant to be followed by a ten-minute discussion, there is, of course, no way to introduce a joint process of knowledge generation. In Prague, despite some scepticism from the delegates at first, we saw to it that the time frame for presentations and discussion were virtually equal, which, in a trivial sense, was perhaps the single most innovative aspect of the conference. 
Although it initially caused uncertainty, in the end this is what participants praised most enthusiastically as an original conference experience, and it ultimately led to a reformatting of the insights into the content with respect to the ethos and ethics of their scientific and artistic approaches to their work. The alternative to the standard conference format here was precisely not that of a one-directional TED Talk but a collective process that enabled a real exchange and generation of knowledge, precisely using the example of engaging with form(at)s $s^{7}$. The question How does Performance Philosophy act? puts us back on the trail of Heidegger's question when in What is Philosophy? he writes:

When we ask, 'What is philosophy?' then we are speaking about philosophy. By asking in this way we are obviously taking a stand above and, therefore, outside of philosophy. But the aim of our question is to enter into philosophy, to tarry in it, to conduct ourselves in its manner, that is, to 'philosophize'. The path of our discussion must, therefore, not only have a clear direction, but this direction must at the same time give us the guarantee that we are moving within philosophy and not outside of it and around it. The path of our discussion must, therefore, be of such a kind and direction that that of which philosophy treats concerns us personally, affects us and, indeed, touches us in our very nature (Heidegger, 1956, p. 20-21).

Do you see a connection here? Do we not need to study carefully how philosophy acts in order to understand what philosophy is?

A.L.: Every process of philosophical thought is evoked by being touched or affected by an idea or a phenomenon. And at the same time, why do we pursue philosophy at all? Is it just to advance academically? This opens up an interesting field for dialogue. Both questions pertain to actions, and questions pertaining to actions are always questions of performativity, and questions of performativity are always (also) questions of forms of performance. In the first instance it is not essentially about examining performance in the sense of theatre studies, but would it really be too far-fetched to develop something that could represent performance analysis in the sense of a scrutiny of form within philosophy? This would mean that as good scholars we would be compelled to be innovative in our formats. Richard M. Carp expresses it as follows:

The test of thought, then, is its ability to contribute to practices of living well. Because the universe is surprising, these practices cannot be static sets 
of skills, but must include the ability to respond appropriately in a dynamic context. Many factors contribute to the dynamism of the world, which appears wherever we look. [...] Our (partial) understanding guides us to act in ways that have unexpected results, to which we must respond in novel and unanticipated ways. [...] The actions our understanding helps shape today will (sometimes) create circumstances that call for new understandings and new actions. Part of what we need to know is how to change. We must 'make room for surprises and ironies at the heart of all knowledge production; we are not in charge of the world' (Haraway, 1996, p. 125 apud Carp, 2001, p. 74).

The question of how must be considered essentially relevant to the question of what. Therein surely lies a blind spot of academic philosophy today. To be clear: When we ask, How do we want to live? we must surely look closely at our own performances; it cannot only be a question of performativity in general theoretical terms, but must take into account and critically address our own embodied habitualised - and changeable - forms of action.

A.S.: I keep wondering how, when and why this impoverishment of the diversity of forms came about in academic philosophy, not only in the performance practices of physical co-presence, but also in written formats. Naturally, claims regarding what counts as scientific have changed over the course of time: Plato would doubtless be regarded as unscientific today, to say nothing of Nietzsche and Augustine or indeed even Descartes and Wittgenstein. But can we not perhaps find in that a challenge to innovate the form of our claims to be scientific? This would certainly require that we do not simply regard them as given and unchanging but that we necessarily re-evaluate our own courage, even to fail, lest we corrupt our own philosophical content. Is it not, perhaps, then necessary that we learn from the artistic practice of always testing which content demands which form? It is certainly no coincidence that Heidegger uses the metaphor of Holzwege (meaning literally both logging paths and detours as in wrong tracks; sometimes translated as off the beaten path) when asking about the origin of the work of art (it would have been a whole different story had he titled the volume, say, Highways!).

A.L.: One common objection to experimental forms of philosophizing that take up precisely this logic of artistic research in order to explore innovative formats for new content alleges that they tend to result in either bad art or 
bad science. Regrettably, this may indeed sometimes be the case, and of course anything that leads to bad art or bad science is not acceptable. It cannot be a question of fostering dilettante philosophy at the expense of good thought or producing bad art for the sake of philosophic innovation. But in my view, this very problem calls for us to engage with these questions more, not less. Conversely, it is not the case that the standardized formats that are currently the norm necessarily guarantee high scientific quality - the only thing they guarantee is that a particular scientific form is repeated. It is perfectly possible to spout out all sorts of nonsense in a formally impeccable way. I would therefore argue against being lulled into a dangerously false sense of security that a specific form could guarantee highquality content. We ought rather to endeavour to ensure that high-quality content is presented in high-quality formats - meaning well-considered formats appropriate to the particular content. This may indeed involve standardized forms, but it can also mean that it might be necessary to develop new ones. The question must be re-examined at every instance and in each case. And the aforementioned courage to fail naturally plays a significant role in this. Without the courage to fail, one cannot be open to the results of one's research. Openness to the results, however, is a necessary condition for good science.

A.S.: Recently, I became acutely aware of such a contradiction when I attended a lecture on forms of representing critique, in which the speaker read out (or mumbled rather) a highly academic text such that those of us in the audience could in fact hardly understand anything at all (something that nobody dared criticize). I had the impression that his chosen form completely undermined his content. I call such phenomena performative contradictions: the form negates the content and vice versa. In the performing arts, it is quite common to play with contradictions of this kind. We are all familiar with scenes from the theatre or in films when a character with a bright red face screams: I AM NOT ANGRY!!! (This example also gives a sense of how much a form of presentation determines our perception on the audience's side.) In scientific performances, such connections are usually ignored, but of course they play a role anyway. The question is simply whether we can put ourselves in a position to reflect on this. 
A.L.: We are also circling around questions of incorporated and habituated knowledge here. It is important to me to understand more about how theory is embodied. I often wonder what it might mean to philosophize physically, or what the body of a philosophy is.

A.S.: Personally, I have certain difficulties with the concept of so-called body knowledge. To me, it seems to imply an alternative that makes no sense at all. I mean, what is body-less knowledge supposed to be? Surely, knowledge that is not tied to bodies is sheer information; it always requires a subject, that is, a body, to interpret this information, that is to say, to organize knowledge. I prefer the term "implicit knowledge," as Polanyi coined it in his formulation "We know more than we can tell" (Polanyi, 1983, p. 4), since there are, of course, forms of knowledge that cannot be explained - or only with difficulty - in language (much less in writing). Is that what you mean?

A.L.: Yes and no. It is, no doubt, also about implicit forms of knowledge, but to a certain extent it is also about democratizing parts of the body. You are right, of course, that there is no such thing as body-less philosophizing. Nevertheless, I wonder how to cope with the hyper-intellectual aspect of philosophy without turning it into something that cannot be taken so seriously.

A.S.: Presumably you are talking about democratizing forms of perception? Of course, eyes, noses, mouths... are all parts of the head, and brains, as far as we know, organize not only rational processes but all the others as well. The whole hierarchizing of these processes is, neurologically speaking, long since outdated, but the sciences (including the natural sciences) continue to operate with the hierarchy of so-called rational versus irrational or cognitive versus sensory approaches. This whole manner of speaking has long become quite untenable and urgently needs to be replaced (which would be, by the way, a task for philosophy, in my view).

A.L.: I agree. Nevertheless, we must reflect rigorously not only on the formats and presentation forms for philosophical results but also precisely on what forms of generating philosophical insights can still exist. Perhaps it is not the best form, but sitting at our desks all day is certainly not the only way to pursue philosophy: 
Specific disciplines of the body correspond to specific experiences of the world. Academic thought is produced by a specifically disciplined body, one that can tolerate sitting for hours in sterile rooms buzzing with the sound of fluorescent lights, listening to word after word after word of lecture after lecture. These bodies have been taught to dissociate from themselves, trained to delay elimination (and even the experience of the need to eliminate), to repress the experience of sexual desire, hunger, and thirst, to still the urge for movement and kinesthetic expression for slumberous physical stillness which is required not only for attending (conferences, classes, laboratories) but also for reading, writing and computer work (Carp, 2001, p. 99).

We could explore other (including also physically other) practices for processes of philosophical cognition. For example, walking has a certain philosophical tradition, or as Rousseau put it: "There is something in walking which animates and enlivens my ideas. I can scarcely think when I remain still; my body must be in motion to make my mind active" (Rousseau, 1996, p. 157). And likewise Montaigne: "My mind will not budge unless my legs move it" (Montaigne apud Desan, 2016, p. 3). ${ }^{8}$ Nietzsche formulates it most radically: "Sit as little as possible; give no credence to any thought that was not born outdoors while one moved about freely - in which the muscles are not celebrating a feast, too. All prejudices come from the intestines. The sedentary life - as I have said once before - is the real sin against the holy spirit" (Nietzsche, 1989, p. 239-240) ${ }^{9}$ And as Carp, too, reminds us, we are not simply incorporeal in our practices but have learned a specific form of physical discipline. However, this specific form is one that demands a number of dissociative abilities, and we should therefore ask ourselves whether it is (always) the appropriate way to help bring to bear our need for completeness of insights.

A.S.: This is indeed another blind spot of contemporary academic philosophy, and I have to admit that I am not immune to this myself. Although I am not only influenced by philosophy but also by the theatre, and although as a dramaturge in that field I am very explicitly responsible for developing formats, until just a few years ago I was unable to apply this expertise to developing academic formats. It was truly a crucial insight for me when in 2013 I experienced your work with the Centre for Performance Studies/Theater der Versammlung zwischen Bildung, Wissenschaft und Kunst (Theater of Assemblage among Education, Science and Art) $(\mathrm{ZPS} / \mathrm{TdV})^{10}$ at the 
University of Bremen (Germany). I think the seminar you were leading back then was precisely about different ways of embodying and performing philosophy, and I was present when the TdV made one of its so-called Performance Visits to your philosophy seminar. It was phenomenal to see how a small performance could transform the whole quality of thinking and the tone and intensity of discussion in the class and how it really contributed to knowledge streams in the participants. I went away profoundly impressed. And even today I cannot explain why I (even in my capacity as a dramaturge) never came up with the idea of applying performative strategies in my philosophy seminars! However, this fact seems to me to illustrate not only my individual inability but is also symptomatic of the consequences of certain processes of discipline in both fields. In this case my sense for the alternative (as discussed at the beginning) had been truly amputated. A certain rigidity of forms had clearly limited my ability to think as well. And I say that even though I was still studying in the older Magister programme (and teaching as well). That same effect must be even stronger nowadays in the extremely linear formats of bachelor's and master's programmes, which prevent deviations, or at least make them even more difficult than before.

A.L.: And now you have been working at the ZPS/TdV yourself for more than five years and have become in a sense an expert in provoking people's sense for alternatives, as is clear from the dramaturgy your developed for the Performance Philosophy Conference in Prague. Can you specify what made this sense for alternatives possible for you?

A.S.: Yes, I think that it has to do with the truly interdisciplinary way of working at the ZPS/TdV. I say truly because for some time now there have been many interdisciplinary working contexts in which interdisciplinarity exists only on paper. Nor is that surprising, because the structures, especially the temporal structures, often do not allow a real engagement to take place. A real engagement is, firstly, always also a deconstruction, which is necessary, in my view, if the point is to learn to see one's own blind spots (through the gaze of others), to call into question things that are taken for granted.

A.L.: That has been my experience as well. The attitude of practising philosophy only for philosophers seems deadly to me; it fails even measured by its own objectives. What makes philosophy relevant if it is not its claim to of- 
fer a contribution to the question of the good life? And if such a contribution can be made, it must surely be from the perspective of the actual lifeworld and its current challenges. Philosophy must remain susceptible, infectible, so to speak, in order to remain relevant. Otherwise it becomes nothing but a brain-game for nerds. It has to follow an endless movement of opening and closing, has to remain receptive, and must not seal itself off hermetically. This applies to the exchange with other disciplines, but also beyond academia, to the way it engages with the world.

A.S.: Strangely, it seems to me that this sealing off from other disciplines and extra-academic influences (not only in philosophy) appears to have increased, not decreased, with digitization. After all, digitization in principle promises unsuspected opportunities of networking. The way it's employed, however, (especially in the university context of e-learning), has had the de facto effect of separating the disciplines instead of allowing new ways for them to interconnect. For example, while it used to be possible - and common practice - to place a text from another discipline on course reserves at the library, with some E-Learning-Tools it is not even possible to get access to a text from another seminar even in the same discipline without registering for that seminar...

A.L.: In the context of Performance Philosophy, the question is occasionally raised as to whether the whole fuss about performativity in philosophy could not perhaps be seen as another building block in the trend to selfrepresentation in the digital world. That is to say, also in the spirit of neoliberal approaches to the discussion of performance as performative skills that serve merely to market content better. It has been suggested, in that context, that Performance Philosophy joins in such trends to optimize the packaging without improving the content. On the other hand, the philosophical practices that have forgotten performativity are almost glorified as practices that rebel against such neoliberal trends. That is, of course, nonsense. Even if there are philosophical practices that do not reflect on their own performativity, they nevertheless have performative qualities that obviously produce effects as well. The point is not to make performers of philosophers artificially, or to make philosophers of performers; rather, doing philosophy has always constituted and involved a performative act, for its very doing has to be (re)presented in one way or another. So a philosopher 
necessarily always performs something when he or she does philosophy. Performance Philosophy is simply about making it possible to reflect on these performative qualities and thus opening them up for negotiation.

A.S.: Still, Performance Philosophy should very much be understood as a sign of the times. The performative turn in philosophy goes hand in hand with an increased interest in questions of the performative elsewhere. More correctly, one should say, it goes hand in hand with an increased interest in questions regarding the content of the performative, since in form the linguistic turn still operates under the motto of understanding everything as text. It seems to me that this motto is another reason that we can report that university education suffers from an immense surplus of text-based knowledge transmission. The university for the masses and digitization have naturally contributed to this as well, but it is notable that digitization in particular makes very different forms available for imparting knowledge, yet this opportunity has remained largely unexploited to date. Indeed, digital progress (within the humanities in particular) presents something of a sad example of what happens when formats are not reflected upon. Scientific circles have thus far done far too little with the possibilities of the new digital formats, so that in many cases they have done more to reduce rather than expand the performative range of the various disciplines. Several years ago, Michel Serres wrote a pleasingly subversive little book in which he addressed such possibilities and came to the conclusion that we have to rethink the tasks of our educational institutions from the bottom up. Schools and universities are no longer the exclusive guardians of knowledge; access to knowledge is now possible through so many more channels, that we no longer have to make the imparting of knowledge content our number one priority. At stake, rather, is how to deal with the knowledge that is available. He asks:

Why have these innovations not taken place? I hesitate to accuse philosophers (I consider myself to be one of them), although their vocation is to anticipate the knowledges and practices to come, and it seems to me that they have failed in this task. Preoccupied with day-to-day politics, they have not perceived the arrival of the contemporary (Serres, 2015, p. 15).

For me, this is related to the question you raised earlier in relation to philosophy for philosophers (the same would apply to theatre for theatre people). 
Today, there are many - very many - urgent topics towards which it would be desirable, in these times of great processes of social upheaval, for philosophy - as well as art - to work out attitudes. But this urgently requires a reorientation of university practices, namely, in the spirit of actual interdisciplinary and transdisciplinary networking rather than by separating disciplines - a very promising measure.

A.L.: Here I feel reminded of what we wrote recently in the introduction to our latest volume of essays:

Today, encountering the foreign has become a topic in more and more social realms. Strangers are increasingly coming into countries that are foreign to them, and some of the long-established inhabitants of those countries are responding strangely. At the same time, so-called filter bubbles on the internet are preventing or at least making it more difficult for people to encounter the unfamiliar, and indeed any kind of encounter at all is increasingly at risk of becoming something strange and foreign in the age of acceleration and digitization (Lagaay; Seitz, 2018, p. 12).

This is related to what inter- and transdisciplinary processes of exchange can teach: the encounter with the strange and the productive making strange of one's own habits. We cannot allow the strain of the sheer mass of information that descends on us daily to cause us to become comfortable or even lethargic. Nor can we allow it to reduce us to taking refuge in standardized procedures from which we tolerate no deviations. I find that the contrast of beaten paths versus highways applies very well here too: Sometimes one gets lost because they aren't yet well enough beaten, but that is precisely what makes them into paths of the sciences! On highways, by contrast, one moves at great speed but always rigidly in one direction; any deviation can be life-threatening. We cannot allow these to be the qualities that characterize paths of knowledge in universities.

\section{Notes}

1 See CBC Comedy (2016) and TEDx Talks (2015).

2 See also Chandler (1994).

3 See Expedition Philosophie E.V. (2012).

4 See Soundcheck Philosophie (2013). 
5 See Performance Philosophy (2019).

6 The Third Biennale Performance Philosophy Conference, "How Does Performance Philosophy Act? Ethos, Ethics, Ethnography", was held from June 22 to 25, 2017 at the Academy of Sciences and the Academy of the Performing Arts in Prague. For the conference programme and additional information, see: <http://web.flu.cas.cz/ppprague2017/manifest.html>. Accessed on: March 6, 2019.

7 Also see: Holkenbrink \& Seitz (2018, p. 137-150).

8 Michel de Montaigne, Essais, III, 3, 629 C (828): “Mon esprit ne va, si les jambes ne l'agitent".

9 Friedrich Nietzsche, Ecce homo (1889) / Warum ich so klug bin, $\$ 1$.

10 The Bremen based Theater der Versammlung (Theater of Assemblage) is one of the very first research theaters in Germany (Artistic Director: Jörg Holkenbrink). Based at the Center for Performance Studies at Bremen University, Theater der Versammlung brings together students, scientists from all faculties, and professional performance practitioners to work together on a range of themes and questions that arise within academic contexts, using methods and means drawn from performance art and theatre. This results in an intense collaboration with people whose expertise is in a wide range of different discourses. The performances that emerge from this interdisciplinary work process have been presented and discussed throughout the German speaking world and beyond, and in a range of different professional and educational contexts including businesses, schools, health institutions and cultural centers. The Performance Studies curriculum at Bremen University is explicitly geared towards training students in the forms and methods of the theatre's investigatory, engaged and interventionist approach to performance. Jörg Holkenbrink is the artistic director of both the theater company and the Center for performance Studies at Bremen University. See: <https://www.tdv.uni-bremen.de/konzept.php\#EN>. Accessed on: April 30, 2019.

\section{References}

BIENNALE PERFORMANCE PHILOSOPHY CONFERENCE, 3., How Does Performance Philosophy Act? Ethos, Ethics, Ethnography, 2017, Prague. Conference programme and additional information. Prague: Academy of Sciences and the Academy of the Performing Arts, 2017. Available at: 
<http://web.flu.cas.cz/ppprague2017/manifest.html>. Accessed on: March 6, 2019.

CARP, Richard. Integrative Praxes: Learning from Multiple Knowledge Formations. Issues in Integrative Studies, Boone, v. 19, p. 71-121, 2001. Available at: <http://libres.uncg.edu/ir/asu/f/Carp_Richard_2001_Integrative.X.pdf>. Accessed on: April 30, 2019.

CBC COMEDY. 'Thought Leader' gives talk that will inspire your thoughts: CBC Radio (Comedy/Satire Skit). (4m15s). June 8, 2016. Available at: $<$ https://www.youtube.com/watch?time_continue $=34 \& v=\_Z B K X-6 G z 6 A>$. Accessed on: April 30, 2019.

CHANDLER, Daniel. The Transmission Model of Communication. 1994. Available at: <http://transcriptions-2008.english.ucsb.edu/archive /courses/warner/english197/Schedule_files/Chandler/Transmission.model_files/tr ans.htm>. Accessed on: April 30, 2019.

DESAN, Philippe (Ed.). The Oxford Handbook of Montaigne. Oxford: Oxford University Press, 2016.

EXPEDITION PHILOSOPHIE E.V. Website. Leipzig, 2012. Available at: <https://expeditionphilosophie.wordpress.com>. Accessed on: April 30, 2019.

FISCHER-LICHTE, Erika. Performativität: Eine Einführung. Bielefeld: Transcript, 2015.

HEIDEGGER, Martin. What is Philosophy? Translated and with an Introduction by William Kluback and Jean T. Wilde Ncup, Inc. (formerly New College and University Press, Inc.). Albany, NY, 1956.

HOLKENBRINK, Jörg; SEITZ, Anna. Challenging Formats: Content and Form in Dialogue - On the development of aesthetic sensitivities in academia. In: AHMAD, Aisha-Nusrat; FIELITZ, Maik; LEINUS, Johanna; SCHLICHTE, Gianna Magdalena (Ed.). Knowledge, Normativity and Power in Academia: Critical Interventions. Frankfurt; New York: Campus, 2018. P. 137-150.

LAGAAY, Alice; SEITZ, Anna (Ed.). Wissen Formen - Performative Akte zwischen Bildung, Wissenschaft und Kunst: Erkundungen mit dem Theater der Versammlung. Bielefeld: transcript, 2018.

NIETZSCHE, Friedrich. Ecce Homo. [1889]. Translated, Edited \& With Commentary by Walter Kaufmann. New York: Vintage Books, 1989. 
PERFORMANCE PHILOSOPHY. A research network for the field of Performance Philosophy. Website. 2019. Available at: <http://performancephilosophy. ning.com/group/philosophy-on-stage>. Accessed on: April 30, 2019.

POLANYI, Michael. The Tacit Dimension. Gloucester, MA: Peter Smith, 1983.

ROUSSEAU, Jean-Jacques. The Confessions. [1770]. Ware: Wordsworth Editions, 1996.

SERRES, Michel. Thumbelina: The Culture and Technology of Millennials. London; New York: Rowman \& Littlefield International, 2015.

SHANNON, Claude; WEAVER, Warren. The Mathematical Theory of Communication. Illinois: The University of Illinois Press, 1979.

SOUNDCHECK PHILOSOPHIE. Philosophie-Performance-Festival. Website. Leipzig, 2013. Available at: <https://www.soundcheckphilosophie.de>. Accessed on: April 30, 2019.

TEDX TALKS. Como parecer inteligente na sua palestra TEDx: Will Stephen, TEDxNewYork. (5m55s). Jan 15, 2015. Available at: <https://www.youtube.com/watch?v=8S0FDjFBj8o >. Accessed on: April 30, 2019.

THEATER DER VERSAMMLUNG. Zentrums für Performance Studies. Website. Bremen: Universität Bremen, 2015. Available at: <https://www.tdv.unibremen.de/konzept.php\#EN>. Accessed on: March 6, 2019.

Alice Lagaay is professor for Aesthetics and Cultural Philosophy at Hamburg University of Applied Sciences (Germany). Researcher on the concept and phenomenon of creative indifference, focusing its formulation in the works of Salomo Friedlaender/Mynona. Founding core convenor of the Performance Philosophy international research network, co-editor of the Performance Philosophy book series at Palgrave Macmillan.

ORCID: http://orcid.org/0000-0002-2455-3238

E-mail: alice@do4d.com

Anna Seitz is Dramatic adviser, philosopher and scholar in Theatre, Film and Media Studies. She teaches at the Centre for Performance Studies at Bremen University and at Hamburg University of Applied Sciences. Member of the Theater der Versammlung zwischen Bildung, Wissenschaft und Kunst). Scholarship hold- 
er by Hans Böckler Foundation for her PhD in philosophy which focuses on performative research and performance in research.

ORCID: http://orcid.org/0000-0002-7987-7854

E-mail: anna.seitz@web.de

This original paper, translated from the German by Steven Lindberg and Alice Lagaay, is also published in Portuguese in this issue of the journal.

Received on May 5, 2019

Accepted on October 1, 2019

Editor-in-charge: Patrick Campbell Editor-in-charge: Laura Cull Ó Maoilearca Editor-in-charge: Luciana da Costa Dias

This is an open-access article distributed under the terms of the Creative Commons Attribution License 4.0 International. Available at: <http://creative commons.org/licenses/by/4.0>. 